\title{
SEBARAN DAN KONDISI EKOSISTEM PERAIRAN DI PULAU PANAMPEANG POLEWALI MANDAR
}

\section{DISTRIBUTION AND CONDITIONS OF WATER ECOSYSTEM IN PANAMPEANG ISLAND, POLEWALI MANDAR}

\author{
Muh Isman $^{1 *}$, Chair Rani ${ }^{1}$, Abdul Haris ${ }^{1}$, Ahmad Faizal $^{1}$ \\ Diterima: 3 Juli 2019 Disetujui: 10 Juli 2019
}

\begin{abstract}
ABSTRAK
Ekosistem pesisir seperti mangrove, lamun dan terumbu karang akan mengalami kerusakan dapat diakibat oleh faktor abiotik dan gangguan akibat manusia (anropogenik). Penelitian ini bertujuan untuk mengetahui jenis, sebaran dan kondisi ekosistem di pulau panampeang Polewali Mandar. Penelitian ini dilaksanakan pada bulan April sampai Desember 2018 pada Pulau Panampeang di Kecamatan Binuang Kabupaten Polewali Mandar Sulawesi Barat. Sampling Mangrove menggunakan plot berukuran $10 \mathrm{~m}$ x $10 \mathrm{~m}$ mempunyai Empat stasiun pengamatan dengan Tiga kali pengulangan setiap stasiun dengan jarak pengulangan $5 \mathrm{~m}$. Sampling pengambilan data padang dengan estimasi penutupan lamun dilakukan dengan cara membentangkan transek garis sepanjang $100 \mathrm{~m}$ dan menempatkan kuadran $0,5 \times 0,5 \mathrm{~m}^{2}$ dengan kisi-kisi pada interval jarak 20 meter. Transek ini dilakukan pada lokasi yang memiliki ekosistem padang lamun dan pengambilan data ekosistem terumbu karang dilakukan dengan menggunakan metode RRA (Rapid Reef Assessment). Hasil penelitian jenis mangrove yang ditemukan pada pulau-pulau kecil Polewali Mandar yaitu Rhizophora mucronata, Avicennia alba dan Sonneratia alba. Secara umum kondisi kerapatan mangrove sangat padat. Secara umum kondisi tutupan lamun baik dan secara umum kondisi penutupan karang hidup (live coral) rusak buruk.
\end{abstract}

Keywords: ekosistem pesisir, identifikasi jenis, kondisi, pulau panampeang

\begin{abstract}
Coastal ecosystems such as mangroves, seagrasses, and coral reefs will suffer damage due to abiotic factors and human (anthropogenic) disturbances. This study aims to determine the type, distribution, and condition of ecosystems on the Panukeang island of Polewali Mandar. This research was conducted from April to December 2018 on Panampeang Island in Binuang District, Polewali Mandar Regency, West Sulawesi. Mangrove sampling using a $10 \mathrm{~m} \times 10 \mathrm{~m}$ plot has four observation stations with three repetitions of each station with a repetition distance of $5 \mathrm{~m}$. A sampling of field data collection with an estimation of seagrass closure was carried out by stretching a $100 \mathrm{~m}$ line transect and placing a quadrant of $0.5 \times 0.5 \mathrm{~m} 2$ with a grid at intervals of 20 meters. This transect was carried out at locations that have seagrass ecosystems, and data collection on coral reef ecosystems was carried out using the RRA (Rapid Reef Assessment) method. The results of the research on the type of mangrove found on the small islands of Polewali Mandar were Rhizophora mucronata, Avicennia alba, and Sonneratia alba. In general, the density of mangroves is very dense. In general, seagrass cover conditions are good, and in general, the condition of live coral is badly damaged.
\end{abstract}

Keywords: coastal ecosystems, species identification, conditions, Panampeang Island

\section{PENDAHULUAN}

Ekosistem pesisir merupakan sumberdaya alam yang terdapat di wilayah pesisir yang dapat dimanfaatkan oleh manusia baik secara langsung maupun tidak langsung. Ekosistem pesisir yang dimaksud seperti ekosistem mangrove, ekosistem lamun dan ekosistem terumbu karang. Secara fisik beberapa fungsi dari ekosistem pesisir sebagai melindungai pantai dari gerusan ombak, sebagai filter sedimen tersuspensi, penyerap dan menyimpan karbon. Salah satu pulau di perairan sulawesi barat yang memiliki ekosistem pesisir adalah pulau panampeang.

Korespondensi:

Muh Isman ${ }^{1 *}$

Email: ardiiyong@gmail.com

${ }^{1}$ Departemen Ilmu Kelautan, Universitas Hasanuddin
Pulau Panampeang merupakan gugusan pulau-pulau kecil yang berada di perairan Kabupaten Polewali Mandar Sulawesi Barat. Seluruh daratan utama pulau ini ditumbuhi hutan bakau (mangrove) yang sangat subur. Selain mangrove pulau tersebut memiliki sumberdaya alam lain seperti padang lamun dan terumbu karang. Secara umum fungsi ekologis ekosistem mangrove, terumbu karang dan padang lamun sebagai daerah asuhan, daerah pemijahan dan daerah tempat berlindung bagi biota (Arifin et al., 2004;Isman et al., 2018).

Sebagian ekosistem pesisir di Perairan Polewali Mandar telah mengalami tekanan kepentingan masyarakat. Salah satu ancaman yaitu konversi lahan mangrove menjadi tambak yang merusak ekosistem mangrove dan lamun. Penangkapan ikan yang tidak ramah lingkungan yang membuat terumbu karang rusak (Tamu et al., 2017). 
Salah satu cara yang dilakukan oleh masyarakat sekitar pesisir Polewali Mandar dengan mengkeramatkan Pulau Panampeang melarang segala aktivitas yang akan berdampak kerusakan ekosistem seperti penebangan pohon mangrove, eksploitasi biota laut, penggunaan bom dan bius.

\section{MATERIAL DAN METODE}

Penelitian ini dilaksanakan pada bulan April sampai Desember 2018 pada Pulau Panampeang di Kecamatan Binuang Kabupaten Polewali Mandar Sulawesi Barat. Sampling ekosistem mangrove menggunakan plot berukuran $10 \mathrm{~m} \times 10 \mathrm{~m}$, mempunyai empat stasiun pengamatan dengan tiga kali pengulangan setiap stasiun dengan jarak pengulangan $5 \mathrm{~m}$, kategori kondisi mangrove didasarkan pada Kepmen Lingkungan Hidup nomor 201 tahun 2004, identifikasi jenis menggunakan buku panduan pengenalan mangrove (Noor, 2006). Sampling ekosistem lamun menggunakan plot $0,5 \mathrm{x}$ $0,5 \mathrm{~m}^{2}$ dengan kisi-kisi pada interval jarak 20 meter, kondisi tutupan lamun didasarkan pada Kepmen Lingkungan Hidup nomor 200 Tahun 2004, identifikasi jenis menggunakan dilakukan berdasarkan (Azkab, 1999). Sampling ekosistem terumbu karang dilakukan dengan menggunakan metode RRA (Rapid Reef Assessment) dengan cara snorkling selama 10 menit pada daerah terumbu karang dengan mengamati bentuk pertumbuhan karang dan komponen bentik terumbu karang, kategori kondisi karang hidup (live coral) didasarkan pada Kepmen Lingkungan Hidup nomor 4 Tahun 2001.

\section{HASIL DAN PEMBAHASAN}

\section{Sebaran dan Kerapatan Mangrove}

Secara umum hutan mangrove adalah tanaman pepohonan atau komunitas tanaman yang hidup di antara laut dan daratan yang dipengaruhi oleh pasang surut. Hutan mangrove memiliki fungsi ekologis yang dilihat dari aspek fisika, kimia dan biologi (Arief, 2003). Hutan mangrove umumnya didominasi oleh beberapa spesies mangrove sejati diantaranya, Rhizophora sp., Avicennia sp., dan Sonneratia sp. Spesies-spesies mangrove tersebut dapat tumbuh baik karena memiliki bentuk perakaran yang membantu untuk beradaptasi dengan lingkungan perairan dari pasang surut serta faktor lingkungan lainnya (Isman, 2016). Hutan mangrove di pulau panampeang dilihat secara visual memiliki kerapatan yang sangat padat yang hampir menutupi daratan utama. Hasil identifikasi jenis mangrove pada 4 lokasi stasiun didapatkan hanya 3 jenis mangrove, yaitu Rhizophora mucronata, Avicennia alba, dan Sonneratia alba. Sebaran jenis yang luas yaitu Avicennia alba yang ditemukan pada semua ulangan stasiun penelitian, sedangkan jenis sebaran yang sempit yaitu Sonneratia alba yang hanya ditemukan 1 stasiun penelitian. Sebaran jumlah jenis pada setiap stasiun mangrove di pulau panampeang disajikan pada Gambar 1.

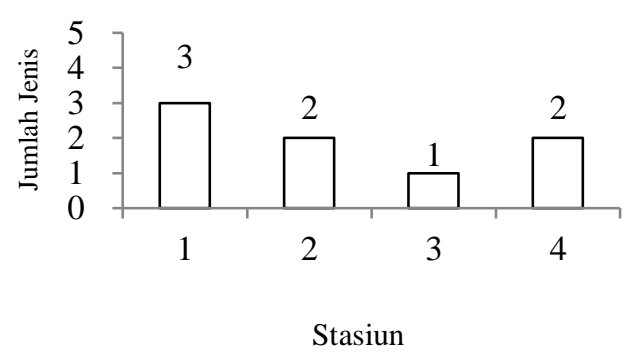

Gambar 1. Jumlah jenis mangrove setiap stasiun di pulau panampeang

Jumlah jenis mangrove yang ditemukan semua stasiun penelitian berkisar $1-3$ jenis. Jumlah jenis terbanyak ditemukan pada stasiun 1. Kerapatan mangrove dalam satuan (Ha) di Pulau Panampeang berkisar $1233-3567$ pohon/ha. Kerapatan tertinggi didapatkan pada stasiun 4, sedangkan kerapatan terendah didapatkan pada stasiun 3 (Gambar 2). Berdasarkan Keputusan Menteri Negara Lingkungan Hidup Nomor 201 tahun 2004, kerapatan mangrove di Pulau Panampeang termasuk kategori (sangat padat), kecuali pada stasiun 3 termasuk kategori (sedang) $(\geq 1000-<1500)$ pohon/ha. Mangrove di pulau panampeang relatif terjaga dari penebangan akibat aktivitas manusia atau kegiatan antropogenik karena pulau ini telah dikeramatkan oleh masyarakat sekitar.

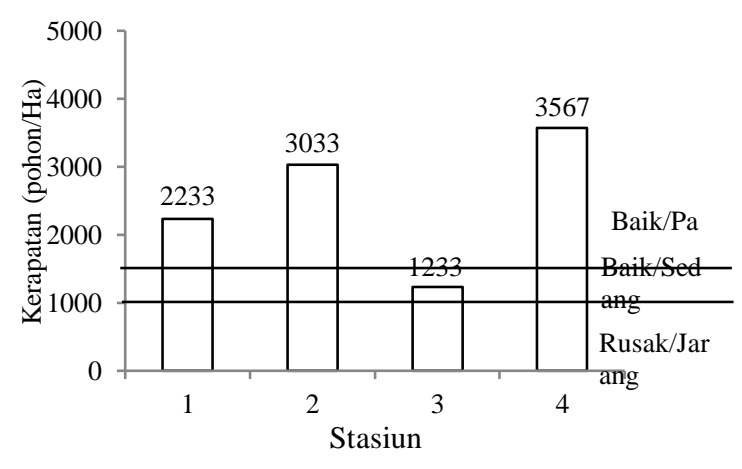

Gambar 2. Kerapatan mangrove satuan (ha) setiap stasiun pulau panampeang

\section{Sebaran dan Persentase Jenis Tutupan Lamun}

Lamun adalah kelompok tumbuhan yang hidupnya dibawah permukaan air laut. Padang lamun merupakan ekosistem yang kompleks dan mempunyai fungsi penting bagi perairan (Arifin \& Supriadi, 2006). Jenis lamun yang ditemukan di perairan Pulau Panampeang Kabupaten Polewali Mandar terdiri dari 5 jenis yaitu, Enhalus acoroides, Thalassia hemprichii, Cymodocea serrulata, 
Halodule pinifolia, dan Thalassodendron ciliatum. Jenis lamun Enhalus acoroides merupakan jenis yang dominan yang didapatkan dengan sebaran yang luas yang ditemukan pada semua stasiun penelitian (Tabel 4 ). Keragaman jenis lamun tertinggi didapatkan di Pulau Panampeang (Stasiun $\mathrm{P} 1$ ), ditemukan 4 jenis sedangkan keragaman jenis lamun terendah didapatkan (Stasiun P3 dan P4) yang hanya ditemukan 2 jenis lamun. Untuk kerapatan individu jenis lamun yang tertinggi didapatkan pada Pulau Panampeang (Stasiun P3) jenis Thalassia hempricii $125,71 \mathrm{ind} / \mathrm{m}^{2}$ sedangkan yang terendah didapatkan pada stasiun P1 jenis Cymodocea serrulata $5,71 \mathrm{ind} / \mathrm{m}^{2}$.

Tabel 1. Sebaran dan persentase tutupan setiap jenis lamun

\begin{tabular}{|c|c|c|c|c|c|c|}
\hline No. & Nama Pulau & Stasiun & Jenis Lamun & $\begin{array}{l}\text { Kerapatan } \\
\left.\text { (ind } / \mathrm{m}^{2}\right)\end{array}$ & $\begin{array}{l}\text { Tutupan } \\
(\%)\end{array}$ & $\begin{array}{l}\text { Kondisi Padang } \\
\text { Lamun }\end{array}$ \\
\hline \multirow[t]{11}{*}{1} & Panampeang & \multirow{4}{*}{ P1 } & Enhalus acoroides & 21,71 & \multirow{4}{*}{84,29} & \multirow{4}{*}{ Baik/ Sehat } \\
\hline & & & Thalassia hemprichii & 98,29 & & \\
\hline & & & Halodule pinifolia & 8,00 & & \\
\hline & & & Cymodocea serrulata & 5,71 & & \\
\hline & & \multirow{3}{*}{$\mathrm{P} 2$} & Enhalus acoroides & 24,00 & \multirow{3}{*}{86,06} & \multirow{3}{*}{ Baik/ Sehat } \\
\hline & & & Thalassia hemprichii & 60,31 & & \\
\hline & & & Thalassodendron ciliatum & 42,46 & & \\
\hline & & \multirow{2}{*}{ P3 } & Enhalus acoroides & 15,43 & \multirow{2}{*}{78,66} & \multirow{2}{*}{ Baik/ Sehat } \\
\hline & & & Thalassia hemprichii & 125,71 & & \\
\hline & & \multirow{2}{*}{ P4 } & Enhalus acoroides & 28,80 & \multirow{2}{*}{68,13} & \multirow{2}{*}{ Baik/ Sehat } \\
\hline & & & Thalassia hemprichii & 100,80 & & \\
\hline
\end{tabular}

Jumlah jenis sebaran lamun di perairan pulau panampeang dapat dilihat pada Gambar 5. Pada stasiun P1 merupakan stasiun dengan kekayaan jenis lamun tertinggi ditemukan 4 jenis sedangkan stasiun P3 dan P4 merupakan stasiun dengan jenis lamun terendah 2 jenis. Pulau Panampeang memiliki jenis lamun yang khas yang jarang ditemukan di perairan lain Sulawesi Barat, yaitu Thalassodendron ciliatum.

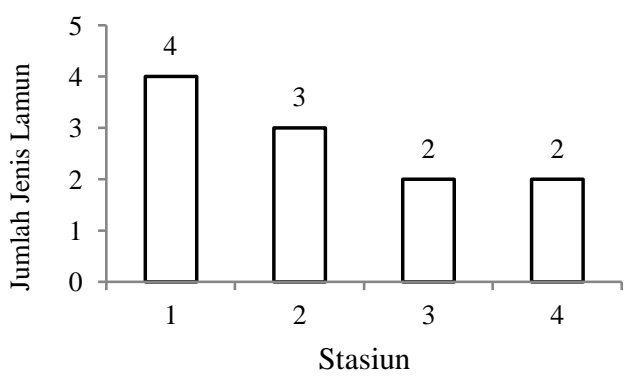

Gambar 3. Jumlah sebaran jenis lamun di perairan pulau panampeang

\section{Tutupan Lamun Setiap Stasiun}

Tutupan lamun pulau panampeang pada semua stasiun penelitian Gambar 6, nilai tutupan total lamun berkisar 68,13 - 86,06\%. Tutupan lamun tertinggi didapatkan pada Stasiun P2 yaitu sebesar $86,06 \%$ sedangkan tutupan lamun terendah didapatkan pada Stasiun P4 dengan nilai tutupan $68,13 \%$, sehingga tergolong kategori baik $>60 \%$ (KMNLH No. 200 Tahun 2004). Baiknya kondisi tutupan lamun diindikasikan karena tidak adanya aktivitas manusia yang telah dikeramatkan oleh masyarakat sekitar, selain itu tingginya tutupan lamun apabila lingkungan perairan yang ditumbuhi oleh lamun itu dalam kondisi baik (Feryatun, 2012).

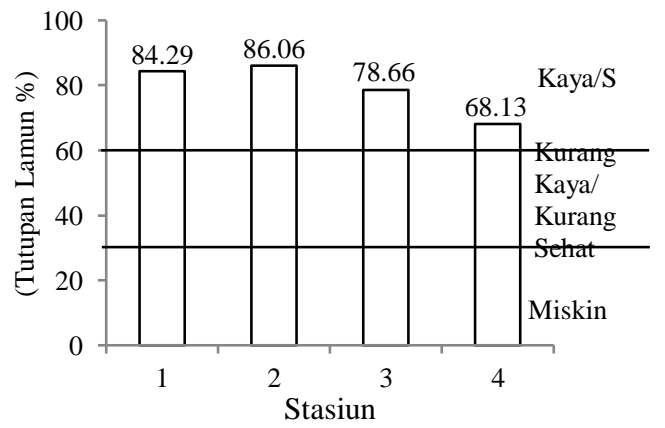

Gambar 4. Nilai dan kondisi tutupan lamun disetiap stasiun

\section{Kondisi Tutupan Terumbu Karang}

Terumbu karang (Coral reef) merupakan organisme yang hidup di dasar perairan dan berupa bentukan batuan kapur $\left(\mathrm{CaCO}^{3}\right)$ yang cukup kuat menahan gaya gelombang laut. Secara ekologi, fungsi terumbu karang sebagai tempat mencari makan, tempat asuhan, tempat pemijahan dan tempat belindung bagi biota (Nontji, 1987). Terumbu karang hidup (live coral) di perairan Pulau Panampeang dalam kondisi (rusak buruk) dengan persentase pada stasiun 1 (1\%), stasiun $2(10 \%)$, dan stasiun 3 (8\%) (Gambar 5). Menurut KepMen-lh No 4. Tahun 2001 persen penutupan karang hidup $0-$ $25 \%$. Penutupan persentase karang mati (DC) pada stasiun $1(11 \%)$, stasiun $2(25 \%)$, dan stasiun 3 $(27 \%)$, sedangkan persentase penutupan karang mati 
yang telah tertutupi alga (DCA) pada stasiun $1(5 \%)$, stasiun 2 (27\%), dan stasiun 3 (18\%) (Gambar 6). Secara teori rendahnya tutupan terumbu karang hidup karena letaknya yang berdekatan daratan pulau menjadi indikasi rusaknya terumbu karang tersebut disebabkan oleh adanya pasokan sedimen yang berasal dari ekosistem mangrove mengakibatkan tingginya sedimentasi yang dapat berdampak kematian karang. Sama hal, Putra 2018, yang mendapatkan sedimentasi yang tinggi mengakibatkan kerusakan terumbu karang. Pemulihan kondisi terumbu karang di perairan pulau Panampeang sangat susah disebabkan kondisi perairan yang keruh dan besarnya penutupan unsur abiotik pada setiap stasiun dengan nilai $70 \%, 35 \%$, dan $40 \%$.

Tingginya nilai tutupan abiotik pada ketiga stasiun tersebut mengindikasikan bessarnya tekanan

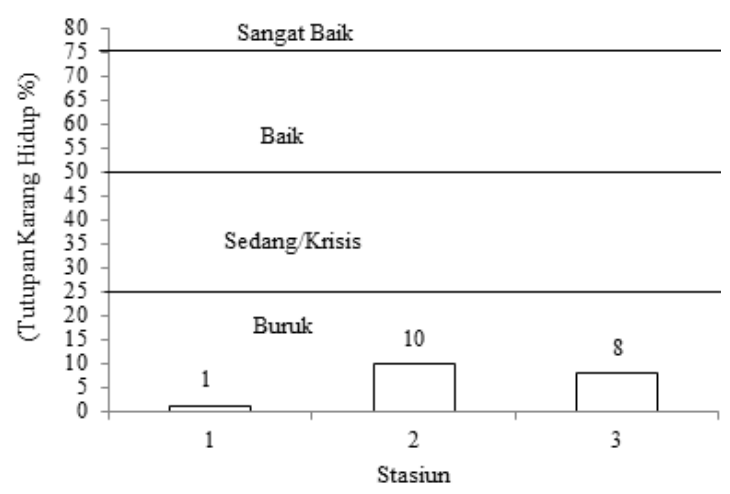

Gambar 5. Tutupan karang hidup dan kondisi terumbu karang di pulau panampeang

lingkungan terhadap ekosistem terumbu karang di perairan pulau panampeang kabupaten polewali mandar. Letak stasiun 1 berada di Utara Timur Laut dari pulau, stasiun 2 berada di Timur, dan stasiun 3 berada di Selatan Barat Daya.
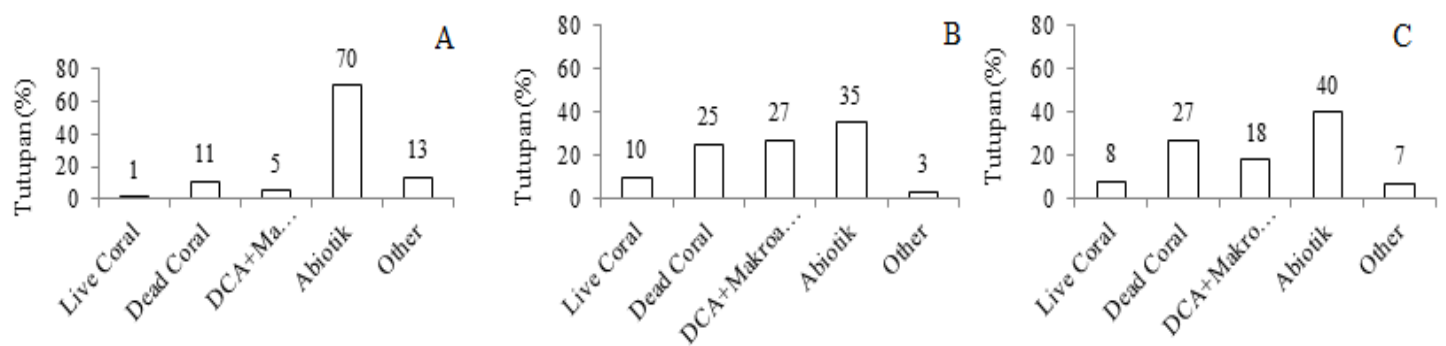

Gambar 6. Tutupan unsur biotik dan abiotik pada stasiun 1 (A), stasiun 2 (B) dan stasiun 3 (C)

\section{KESIMPULAN}

Jenis mangrove yang ditemukan pada pulau panampeang yaitu, Rhizophora Mucronata, Avicennia Alba, dan Sonneratia alba yang secara umum kondisi kerapatan yang sangat padat, jenis Avicennia alba memiliki sebaran yang luas ditemukan pada semua stasiun penelitian. Jenis lamun yang ditemukan yaitu Enhalus acoroides, Thalassia hemprichii, Cymodocea serrulata, Halophila ovalis, Halodule pinifolia, Thalassodendron ciliatum dan Syringodium isoetifolium yang secara umum memiliki kondisi baik, jenis Enhalus acoroides memiliki sebaran yang luas ditemukan pada semua stasiun penelitian, sedangkan untuk terumbu karang yang secara umum memiliki penutupan karang hidup kondisi rusak.

\section{DAFTAR PUSTAKA}

Arief, A. 2003. Hutan Mangrove Fungsi dan Manfaatnya. Kanisisus, Yogyakarta.

Arifin, Y.A. La Nafie. 2014. Studi Kondisi dan Potensi Ekosistem Padang Lamun Sebagai Daerah Asuhan Berbegai Jenis Biota Laut di Perairan Barranglompo Makasssar. Torani 14 (5) : $241-250$.
Arifin \& Supriadi. 2006. Kondisi Padang Lamun Di Perairan Pulau Sabangko, Salemo Dan Sagara Kabupaten Pangkep. ISSN: 08534489. Torani, Vol. 16(2) Edisi Juni 2006: 99 $-106$.

Feryatun. F., Hendrarto. B., Widyorini. W. 2012. Kerapatan Dan Distribusi Lamun (Seagrass) Berdasarkan Zona Kegiatan Yang Berbeda Di Perairan Pulau Pramuka, Kepulauan Seribu. Journal of Management Of Aquatic Resources. Volume, Nomor, Tahun 2012, Halaman 1-7.

Isman. M, Supriadi. M, Werorilangi. S, Isyrini. R, Rastina, Faizal. A, Tahir. A, Burhanuddin. A. I. 2018. Komunitas makrozoobentos pada kondisi mangrove berbeda: hubungannya dengan karakteristik kimia-fisika sedimen.

Keputusan Menteri Negara Lingkungan Hidup Nomor 201. Tahun 2004. Kriteria Baku Dan Pedoman Penentuan Kerusakan Mangrove. Jakarta.

Keputusan Menteri Negara Lingkungan Hidup Nomor 4 Tahun 2001. Tentang Kriteria Baku Kerusakan Terumbu Karang. Jakarta. 
Keputusan Menteri Negara Lingkungan Hidup No 200. Tahun 2004. Tentang Kriteria Baku Kerusakan dan Pedoman Penentuan Status Padang Lamun. Jakarta.

Nontji, A 1987. Laut Nusantara. Penerbit Djambatan. Jakarta.

Noor, R.Y., Khazali, M., Suryadiputra, I.N.N. 2006. Panduan Pengenalan Mangrove di Indonesia. PHKA/WI-IP, Bogor.

Putra, A.W. 2018. Tutupan Substrat Terumbu Karang Pasca Bleaching Akibat Sedimentasi
Tahun 2016 Di Perairan Laut Malili, Kabupaten Luwu Timur, Sulawesi Selatan. Universitas Hasanuddin.

Tamu. Y., Utina. R., Nusantari. E., Kantili. A. S, 2017. Pengelolaan Ekosistem Pesisir Berbasis Sosiokultural dan Pendidikan Karakter di Sekolah Dasar Menuju Kesejahteraan Alam Berkelanjutan. Jurnal Riset dan Kajian Keislaman. ISSN: 20898142 (p). Vol. VI No. 2 Tahun 2017. 